\title{
No s'han de fer ni aguaits ni camins dubtosos en la mar. Obrint nous camins. La tasca del prof. Hauf quant a Ausiàs March.
}

\author{
Vicent MARTINES \\ (UA, ISIC-IVITRA) \\ martines@ua.es
}

El Prof. Hauf ens ha fet, ens fa i farà que els valencians i, en general tots els que esmercem temps — un dels béns més preuats de l'existència- a l'estudi de la Literatura, la Llengua i la cultura de la Corona d'Aragó siguem conscients de 1'immens valor de la nostra història, tal i com, d'altra banda, es constata de manera ben clara a l'ingent volum documental que es conserva als arxius i biblioteques de l'àmbit de l'antic Regne de València, de la Corona d'Aragó i d'altres països europeus, principalment, així com de la resta del món.

Una vegada, ja fa qualque any, vaig escoltar, en un café després d'una densa sessió del simposi internacional celebrat a la Seu Universitària de la Nucia (UA) sobre Curial e Güelfa, dirigit pel Prof. Ferrando, ${ }^{1}$ que el Prof. Albert Hauf — que hi participà amb una ponència molt ben encertada- deia, a propòsit d'una manera de «fer Filologia» que no atén als textos, que només en fa glossa i que, de fet, comporta que hi haja edicions que passen per ser criticofilològiques i que, al remat, manipulen els textos i en canvien el lèxic, la morfosintaxi..., que «No s'han de fer ni aguaits ni camins dubtosos en la mar».

La immensa bibliografia científica (filològica i historicocultural, perquè la Filologia i la Història de la cultura també són ciència!) del Prof. Hauf són un testimoni biogràfic, alhora: són el seu mapa vital, de vocació per la investigació, per l'edició acuradíssima de textos que ha de ser i han de ser la base segura per a qualsevol altra tasca, lingüística o literària. El Prof. Hauf no ha fet mai «glossa d'arguments» ni ha volgut reduir a això la docència d'Història de la Literatura. Sempre ha partit dels textos - fixar-los filològicament—i de la necessitat de situar-los bé en el seu context, a fi i efecte de traure'n l'entrellat adient. I ha estat, és i serà assidu freqüentador dels arxius i biblioteques, ferit com està pel digne dard de la codicologia, l'arxivística, la bibliologia, la paleografia i, en general, de la presa de consciència que, sense veure i tocar els documents i els manuscrits en què se'ns han transmés les obres i/o les vides o els testimonis de vida

1 II Encontre Internacional «Curial e Güelfa: aspectos lingüístics i culturals» (5-8/2/2008), Dtor. Prof. Antoni Ferrando (UV, IEC, RABLB, ISIC-IVITRA). Vegeu: http://www.ua.es/es/estudios/seus/nucia/programacion/2007-2008/curial_guelfa/informacion_general.html [consulta: 20/05/2012]. 
dels autors..., difícilment podrem entendre bé els textos i malament podrem eixir de la caverna de Plató.

Fruit d'aqueixa vocació -en definitiva, quant al Prof. Hauf hem de parlar de vocació per la Filologia - són els seus estudis i publicacions, totes en general, però, especialment - $\mathrm{i}$ deixeu-me que m'agose a destacar-ne només les d'aquesta línia de recerca, confiat que els meus companys en destacaran altres-el que va desenvolupar quant a Ausiàs March.

Quant a Ausiàs March, són remarcables les aportacions del Prof. Hauf, orientades a l'estudi del rerefons moral i filosòfic del discurs amorós del cunyat de Joanot Martorell. Ara bé, em permet remarcar una tasca del Prof. Hauf quant a March: l'inici d'una línia de recerca llavors del tot nova, $1983^{2}$, amb el seu estudi: «El lèxic d'Ausiàs March. Primer Assaig de valoració i llista provisional de mots i de freqüències». Va obrir un camp nou en la recerca filològica sobre el nostre poeta $i$, en general, sobre els nostres clàssics. Pel que explica en aqueix estudi, Hauf va haver d'enfrontar-se a grans dificultats tècniques que a les hores d'ara tenim més resoltes amb programes concrets i de fàcil accés en el mercat (vegeu l'Institut Superior d'Investigació Cooperativa IVITRA, http://www.ivitra.ua.es).

El resultat, en 1983, va ser veritablement engrescador: poder estudiar sistemàticament el lèxic de March, amb les possibilitats de processament de la informació i de les dades que permeten els mitjans informàtics (índex de freqüències, concordances, anàlisi dels contextos, etc.). Aqueix estudi era un primer lliurament dels fruits d'un treball més gran de Hauf: fer la concordança de l'obra d'Ausiàs March. Aquesta tasca, tot i que acabada, per voluminosa, no va poder veure la llum en uns anys en què les dotacions econòmiques a l'altre costat del Canal de la Mànega no donaven per a més — com tampoc les de les administracions espanyoles-.

No s'ha desenvolupat gaire aqueixa línea, ateses les dificultats que l'estudi lingüístic dels clàssics medievals i del Renaixement plantegen sempre. Sí que ho ha estat, però, per la tasca de filòlegs i lingüistes com ara els Profs. Colón, Ferrando o Josep Martines, i, pel conjunt del projecte de diacronía lingüística «Gramàtica del Català Antic» dirigit pel Prof. Josep Martines, al si de l'ISICIVITRA, i amb finançament en convocatòries públiques de l'Institut d'Estudis Catalans, Ministerio (MICINN > MINECO), Generalitat Valenciana a través del Programa Prometeo per a Grups d'Investigació en I+D d'Excel-lència - reconegut oficialment com a Projecte de la UE- i que ha donat lloc a la constitució del Corpus Informatitzat del Català Antic al si del Corpus Informatitzat Multilingüe de Textos Antics i Moderns (http://www.ivitra.ua.es). Aquesta línea iniciada, com s'obrien les rutes de navegació per la procel-losa i atzarosa Mar Oceana, amb dificultats però amb la ferma voluntat i la prudència sempre del mètode filològic, pel Prof. Hauf, ha tingut una continuació en el que va ser la $2^{\mathrm{a}}$

2 Albert Hauf: «El lèxic d'Ausiàs March. Primer Assaig de valoració i llista provisional de mots i de freqüències», Miscel-lània Pere Bohigas, 3, Barcelona, Publicacions de l'Abadia de Montserrat, 1983, pp. 121-124. 
tesi doctoral (Doctorat Europeu) de Vicent Martines, ara en Traducció i Interpretació (sota la direcció del Prof. Víctor Manuel Pina Medina, lingüista), amb un títol que deixa clar la seua integració en aqueixa línia i de la interdisciplinarietat que cal per poder entendre bé els textos: Les traduccions de les poesies d'Ausiàs March a l'anglés. Eines per a l'estudi del llenguatge poètic d'Ausiàs March i de les seues relacions romàniques a partir de les seues traduccions angleses del segle $X X$.

Aquesta tesi i els resultats posteriors, en forma de diversos articles, incideixen sobre l'estudi de les locucions de les poesies de March i va ser un dels primers desenvolupaments específics de la línea iniciada per Hauf; continuats per la Tesi Doctoral Europea d'Elena Sánchez López (UA, sota la direcció de Vicent Martines) (2009); alguns dels resultats de la qual ja han vist la llum en forma de publicacions, i és, a més, en premsa a la prestigiosa editorial alemanya De Gruyter Mouton (data de publicació: 2012). El Prof. Hauf va ser membre del Tribunal d'aqueixa tesi, així com els Profs. Ferrando (UV, IEC, RABLB; president), Max Wheeler (University of Sussex, IEC; vocal), Hans-Ingo Radatz (Universtät Bamberg; vocal) i Sandra Montserrat (UA; vocal). I aqueixa línea de recerca no només ha donat resultat en Filologia Catalana estricta, sinó també en altres àrees de coneixement.

Forma part de diverses institucions: Institut d'Estudis Catalans (Secció Histórico-Arqueològica) [IEC-SHA], Reial Acadèmia de Bones Lletres de Barcelona [RABLB], Estudi General Lul-lià [EGL], Institut Interuniversitari de Filologia Valenciana [IIFV], Institut Superior d'Investigació Cooperativa Institut Virtual Internacional de Traducció [ISIC-IVITRA], Acadèmia Valenciana de la Llengua [AVL].

El Prof. Hauf obri camins i no els ha transitat fent, com diria March mateix, «camins dubtosos en la mar», ni «fent aguaits», sinó fermament i sense amagatalls, sempre a fi de bé. I encara també n'ha obert en la resta de grans temes que ha tractat (Eiximenis, Tirant lo Blanch, Sant Vicent, Sor Isabel de Villena, etc.) $\mathrm{i}$ ha sabut transmetre-ho i transferir-ho als seus deixebles, nombrosos i excel-lents (ha dirigit nombroses tesis doctorals, moltes premiades amb Premi Extraordinari de Doctorat i/o de l'Ixes, que han derivat en nombrosos estudis i publicacions en les editorials i revistes més prestigioses).

El Professor té el valor dels Mestres, dels de debò, dels que amb la seua excel-lència professional i personal són models de compromís per la faena ben feta, una faena que, quant a la Filologia Catalana i el Prof. Hauf, no es queda reclosa en la torre d'ivori de la Universitat, sinó que esdevé una vocació pel bé i l'interés generals. 
